\title{
Registration of Births and Induced Abortions in the Nordic Countries
}

\author{
MIKA GISSLER, Ph.D., Research Professor \\ THL, National Institute for Health and Welfare, Helsinki, Finland \& \\ NHV, Nordic School of Public Health, Gothenburg, Sweden
}

\begin{abstract}
All the five Nordic countries have a long tradition in health statistics and health monitoring. The cornerstone of the national health information systems is register information. There are, for example, complete population-based registration of births and deaths, cancers, hospital care, and medication (Cappelen and Lysol 2004, Gissler and Haukka. 2004, Mortensen 2004, Otterblad Olausson et al. 2004). The main prerequisites for a functioning register system are its completeness and high quality. These are facilitated by the Nordic legislation allowing mandatory reporting from public and private sector without informed consent and the existence of unique person identity number system.
\end{abstract}

Keywords: Register information, health monitoring, population data, live births, stillbirths, abortions, mortality, pregnancy, Nordic countries

\section{Births}

In the Nordic countries, births are covered by three different statistical systems. First, all live births are registered to Central Population Register, which is the basis for vital statistics. Second, all stillbirths and deaths of live born children are registered in Cause-of-Death Register, kept by statistical or health authorities. Third, all Nordic countries have introduced a separate Medical Birth Register for more detailed collection of parturients, deliveries and newborns. Norway was the first to start the national Medical Birth Register in 1967, and Denmark, Iceland and Sweden followed it in the early 1970s. Finland was the last Nordic country to start a similar registration system in 1987 (Gissler et al. 1997). Cross-linkages of register data from these three information systems increase the completeness and quality of birth data in the Nordic countries.

In principle, a Medical Birth Register is relatively easy to start. The numbers are constant and relatively large, round $1-1.5 \%$ of total population in industrialised countries. In the Nordic countries, the total number of live births exceeds 300000 per year (Figure 1). Since the vast majority of births take place in hospitals, the requested information can be gathered from hospitals with birth units (Gissler et al. 2010). According to the most recent data, Iceland $(1.3 \%)$ and Denmark $(0.9 \%)$ has the highest number of planned home births, while the share is between $0.01 \%$ and $0.15 \%$ in the other Nordic countries. Finland and Norway have a separate statistics on unplanned 
home births and births during transportation to hospital. Their shares are $0.2 \%$ and $0.7 \%$, respectively. The Nordic Medical Birth Registers, however, cover even these cases with separate data collection forms.

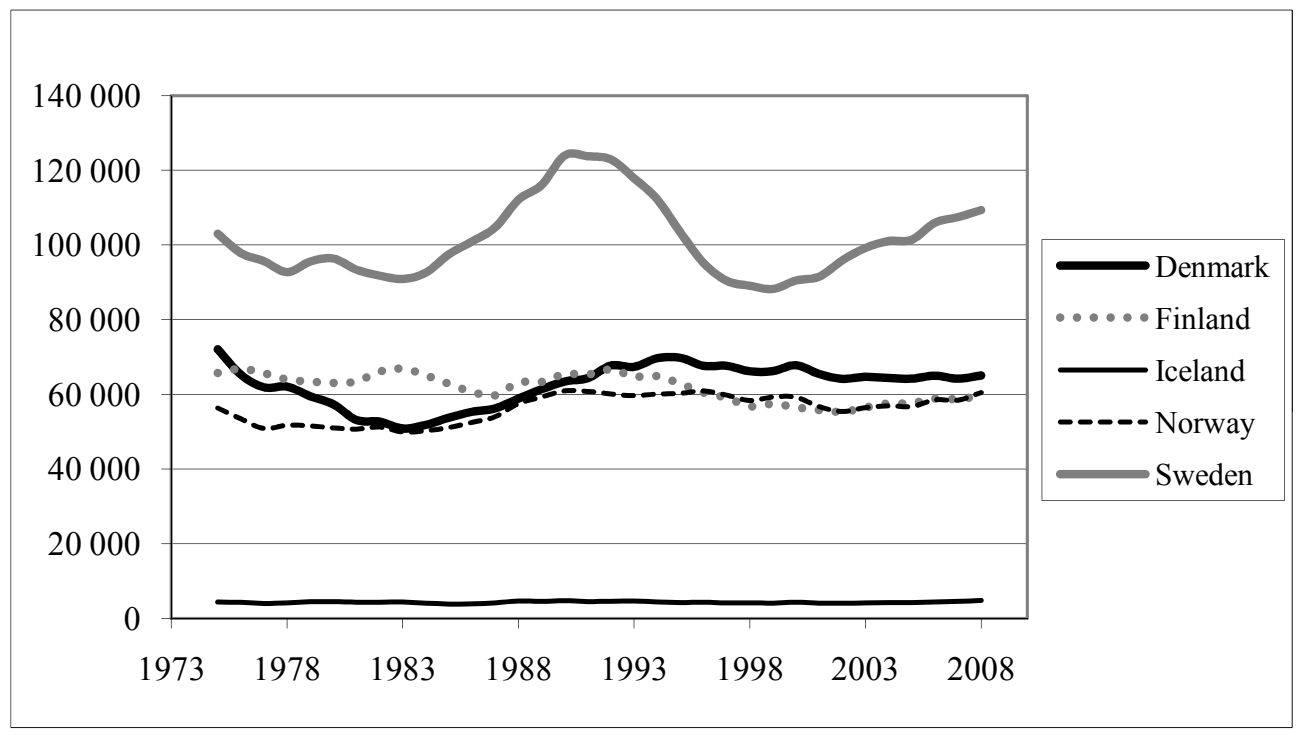

Figure 1. The number of live births in the Nordic countries 1975-2008 (THL 2010).

A further strength for routine data collection of births is that the end-point is clear, at least for live births. For stillbirths, however, different registration criteria and registration principles may apply. Since 2008, all the Nordic countries have used the WHO definition on stillbirths, a gestation age of 22 weeks or a birth weight of 500 grams (WHO 1994). Norway even registers the pregnancies ending between 12 and 22 weeks. Some countries include late induced abortions due to fetal problems in their Medical Birth Registers, but some others exclude them. These cases, however, causes only a minor variation for most of birth statistics because of their very small numbers.

The Nordic countries have different organizations which are in charge of the Medical Birth Registers: a national health authority in Denmark and Sweden (National Board of Health and National Board of Health and Welfare, respectively); a Public Health Institute in Finland and Norway (National Institute for Health and Welfare and National Public Health Institute, respectively). In Iceland, the University Hospital Landspítalinn in Reykjavík is the register keeping organization.

There is a certain variation in the content of the Nordic Medical Birth Registers, but all the registers include information on maternal socio-demographic background, previous pregnancies and deliveries, maternal diagnoses, care and interventions during pregnancy and delivery, and information on newborn health, diagnoses, care and 
interventions. The follow-up ends usually when the child is discharged from the hospital or latest until the end of perinatal period, i.e. the first week of living. Information on deaths, however, can cover the whole infant period until one year of age.

All Nordic Medical Birth Registers include the personal identification numbers for the mothers and their live birth children, but some countries even include fathers' identification numbers. If the information on father is not gathered, this information can be linked from the Population Register for children whose the parents are married or in the case of unmarried couple, if the fatherhood has been confessed through a legal process.

The Register on Congenital Anomalies and Birth Defects are usually closely linked to the Medical Birth Register, either as a separate register or as a part of the Medical Birth Register. Their follow-up period is usually from six to twelve months, and the register covers also induced abortions due to fetal problems (Gissler et al. 2010).

Information on Nordic Medical Birth Registers is published nationally, but also internationally. The Finnish Institute for Health and Welfare (THL) publishes Nordic Perinatal Statistics (THL 2010) every second year. Also the Nordic Medico-Statistical Committee (NOMESCO 2009), OECD (2009), Eurostat (2010) and WHO Regional Office for Europe (2010) collect and present statistics based on these registers.

Medical Birth Registers have been widely used in scientific research. The long-term collection of birth data as well as possibilities to link different registers provides good possibilities for unique studies. These include cross-sectional studies, repeated studies, trend studies, but also longitudinal studies with retrospective data collection or follow-up data. In Norway, for example, the long data collection enables studies of grandmothers, mothers and their children (Nordtveit et al. 2008), or complex study designs within families (Trogstad et al. 2004).

Since the contents of the Nordic Medical Birth Register are relatively similar, several Nordic studies have been initiated. Good examples are for example the Nordic Collaborative project on health and social inequality in early life (NorCHASE) (Mortensen et al. 2008) and the study on the effect on prenatal bereavement exposure to perinatal and childhood health ( $\mathrm{Li}$ et al. 2010). There are also ongoing studies e.g. on perinatal outcomes on children exposed to certain drugs, perinatal outcomes of cancer survivals, survival of low-birth weight children, long-term follow-up of children born after assisted reproduction (MART) and a study on major obstetrical complications (NOSS). These studies have shown that it is feasible to combine information from all Nordic Medical Birth Registers, but sometimes the process can be complicated and timeconsuming, for example due to different content of the registers, data protection issues and limited resources allocated for building large research datasets for researchers. 


\section{Induced abortions}

All the Nordic countries liberalised their legislation on induced abortions in the 1970s. Currently, a woman can get an induced abortion on request until 12 weeks of gestation in Denmark and Norway, and until 18 weeks in Sweden. After that period, permission for pregnancy termination is required from a regional or national board. In Finland and Iceland, a legal indication is always required for an induced abortion. The abortion law is, however, interpreted liberally, and most of the induced abortions are done based on social circumstances (Gissler 1999, Knudsen et al. 2003).

In the Nordic countries, statistics on induced abortions are based on case data on individual level. In Iceland and Sweden, however, the data collection is anonymous, and in Norway, the data collection is anonymous before 12 weeks of gestation. Denmark can identify all induced abortions from its Hospital Discharge Register (LPR Landspatientregister), which includes women's identification numbers. Finland has a separate Register on Induced Abortions and Sterilisations. This register was started to supervise the 1970 legislation on induced abortions and sterilisations, but currently it can only be used for statistical, health monitoring and research purposes.

The data on induced abortions is gathered by the same organisation than Medical Birth Registers excluding Iceland, where the data is compiled and released by collaboration between the Directorate of Health and Statistics Iceland. All countries include information on women's socio-demographic and obstetric background, and on the induced abortion, such as indication (if relevant), gestational age, and the method of induced abortion. Round 80000 induced abortions are reported each year in the Nordic countries. The abortion rate per thousand women in fertile age is the highest in Sweden and the lowest in Finland, while the other three Nordic countries are near the Nordic average (Figure 2). After combining the numbers of induced abortions and deliveries, 22 out of 100 pregnancies end in an induced abortion in the Nordic countries. This percentage is the highest in Sweden (26\%), followed by Norway and Denmark (21\% for both). Iceland (17\%) and Finland (15\%) reports the lowest percentages, Iceland due to its high fertility and Finland due to its low abortion rate (Figure 3).

Information on Nordic Medical Birth Registers is published nationally, but also internationally. The Finnish Institute for Health and Welfare (THL) publishes Nordic Statistics on Induced Abortions (THL 2009) every second year. Also Nordic Medico-Statistical Committee (NOMESCO 2009), Eurostat (2010) and WHO Regional Office for Europe (2010) collect and present at least basic data based on these information systems. 


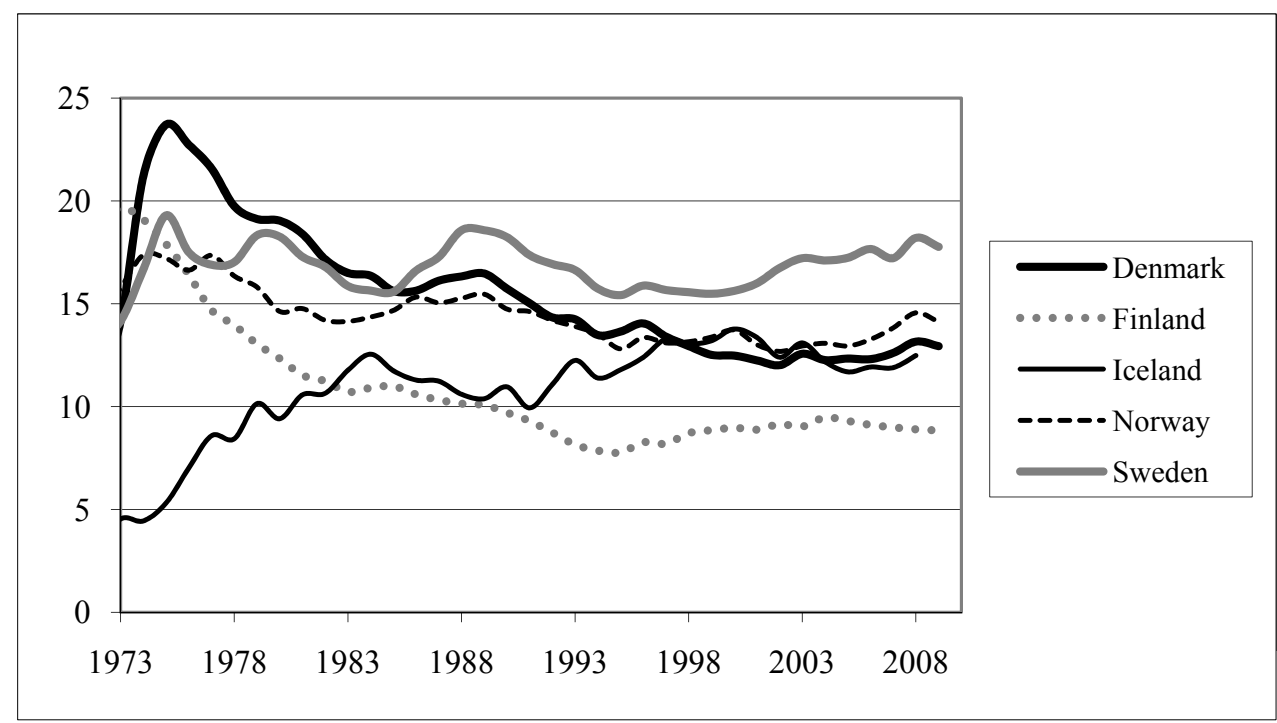

Figure 2. The number of induced abortions per 1000 women aged 15-49 in the Nordic countries 1973-2008 (THL 2009).

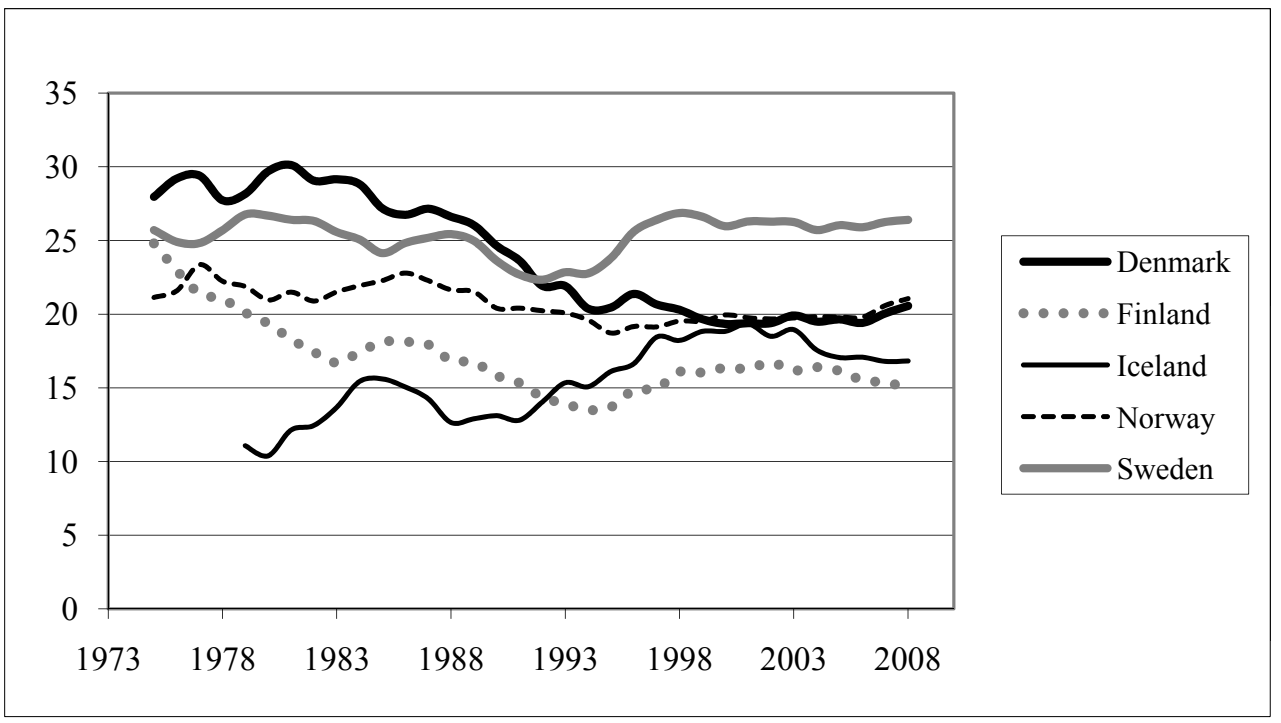

Figure 3. The proportion of induced abortion of the number of induced abortions and deliveries in the Nordic countries 1975-2008, \%. 
The statistics and register information on induced abortions have not been used in research as much as the Medical Birth Register data. Data linkage studies within the Abortion Registers or combining their data with other register sources are only possible in Finland and Denmark. For example the complications (Niinimäki et al. 2009) and repeated induced abortions (Niinimäki et al. 2009, Mentula et al. 2010) after surgical and medical induced abortion have been compared in Finland. Regarding studies linking data with other registers, the risk for adverse pregnancy outcomes in the following pregnancy (Virk et al. 2007), pregnancy-related mortality (Gissler et al. 2004), induced abortions related to subsequent assisted reproduction (Hemminki et al. 2008), and psychiatric diagnosis before and after an induced abortion (Gissler et al. 1996 and Gissler et al. 2010) have been studied. The few Nordic comparisons are limited to statistical comparisons (Knudsen et al. 2003, Knudsen and Gissler 2003).

\section{Future}

This short presentation of the Nordic data sources related to reproductive health shows that there is an increasing trend for using Nordic registers in research. To further increase their use, it is important to maintain the current research-friendly interpretation of data protection legislation in all Nordic countries (Gissler 1999). The delivery of unanonymous data from one Nordic country to another should be allowed without legal restrictions. The possibilities to link different register-based research datasets virtually to larger ones should be explored and piloted in an international context. This also requires new guidelines or in some cases even updates in national data protection legislation and recommendations. Besides legal restrictions, other threats to collection of detailed data on reproduction and to register-based research include reduced resources for statistical offices - which may lead to decreased data quality or even discontinuation of data collection - and reduced research funding (Gissler 1999).

All Nordic countries, especially Denmark, Sweden and Norway, have promoted register-based research since the 1990s. Numerous Nordic register studies indicate that funding has not been an issue, not even in the tight international competition. There has been a general discussion whether there is a need for additional Nordic initiatives to support register-based studies. Examples of such plans include improved and uniform documentation of national registers, advanced education for register-based studies, more frequent Nordic conferences on register-based studies, and specific research programmes for register-based research. A successful example of the last option is the research programme in Longitudinal Epidemiology in 2003-2007, which was financed and run by NordForsk (2010) under the Nordic Council of Ministers. 


\section{References}

Cappelen, I. and H. Lyshol. 2004. Oversikt over helseregistre i Norge (Overview of health registers in Norway, in Norwegian). Norsk Epidemiologi 14: 33-8.

Eurostat. Statistics on Population. Luxembourg, 2010. http://epp.eurostat.ec.europa. eu/portal/page/portal/population/introduction. As accessed 31 August, 2010.

Gissler M, P. Louhiala and E. Hemminki. 1997. Nordic Medical Birth Registers in Epidemiological Research. European Journal of Epidemiology 13: 169-75.

Gissler M., E. Hemminki and J. Lönnqvist. 1996. Suicides after pregnancy in Finland 1987-1994: register linkage study. British Medical Journal 313: 1431-4.

Gissler, M. (Ed). 1999. Aborter i Norden. Induced Abortions in the Nordic Countries. STAKES Statistical Report 10: 1999.

Gissler, M. 1998. Hot mot registerforskning. Sosiaalilääketieteellinen aikakauslehti 36 (2): $183-4$.

Gissler, M and J. Haukka. 2004. Finnish health and social welfare registers in epidemiological research. Norsk Epidemiologi 14 (1): 113-120.

Gissler, M., C. Berg, M-H Bouvier-Colle and P. Buekens. 2004. Pregnancy-associated mortality after birth, spontaneous abortion, or induced abortion in Finland, 19872000. American Journal of Obstetrics and Gynecology 190 (2): 422-7.

Gissler, M., A. Mohangoo, B. Blondel, J. Chalmers, A. Macfarlane, A. Gaizauskiene, M. Gatt, N. Lack, L. Sakkeus and J. Zeitlin for the EURO-PERISTAT group. Perinatal health monitoring in Europe: results from the EURO-PERISTAT project. Informatics for Social and Health Care 2010; 35 (2): 64-79.

Gissler, M., M. Artama, A. Ritvanen and K. Wahlbeck. 2010. Use of psychotropic drugs before pregnancy and the risk for induced abortion: Population-based register-data from Finland 1996-2006. BMC Public Health 10: 383.

Hemminki, E., R. Klemetti, T. Sevón and M. Gissler. 2008. Induced abortions previous to in-vitro-fertilization - an epidemiologic register-based study from Finland. Human Reproduction 23 (6): 1320-3.

Li, J., M. Vestergaard, C. Obel, S. Cnattingus, M. Gissler and J. Olsen. Cohort Profile: the Nordic Perinatal Bereavement Cohort. International Journal of Epidemiology 2010 , in press.

Knudsen, L. B, M. Gissler, S. Bender, C. Hedberg, U. Ollendorff, K. Sundström, K. Totlandsdal and S. Vilhjálmsdottír. 2003. Induced abortion among young women in the Nordic Countries. Acta Obstetricia Gynecologica Scandinavia 82 (3): 257-68.

Knudsen, L. B. and M. Gissler. 2003. The divergent rates of induced abortion among young women in Finland and Denmark. Finnish Demographic Yearbook XXXIX 2003, pp. 227-44. Helsinki: The Population Research Institute, Väestöliitto.

Mentula, M, S. Suhonen, M. Niinimäki, A. Pouta, E. Hemminki, M. Gissler and O. Heikinheimo. 2010. Young age and termination of pregnancy during the second trimester are risk factors of repeat second trimester abortion. American Journal of Obstetrics and Gynecology 203 (2):107: e1-7.

Mortensen, L.H, F. Diderichsen, A. Arntzen, M. Gissler, S. Cnattingius, O. Schnor, G. Davey-Smith and A-M. Nybo Andersen. 2008. Social inequality in fetal growth. A 
comparative study of Denmark, Finland, Norway and Sweden in the period 19812000. Journal of Epidemiology and Community Health 62 2008; (4): 325-31.

Mortensen P. B. 2004. Registerforskning i Danmark (Register research in Denmark, Danish). Norsk Epidemiologi 14: 121-4.

Niinimäki M, A. Pouta, A. Bloigu, M. Gissler, E. Hemminki, S. Suhonen and O. Heikinheimo. 2009. Frequency and risk factors for repeat abortions after surgical compared with medical termination of pregnancy. Obstetrics and Gynecology 113 (4): 845-52.

Niinimäki M, A. Pouta, A. Bloigu, M. Gissler, E. Hemminki, S. Suhonen and O. Heikinheimo. 2009. Immediate complications after medical vs. surgical termination of pregnancy: a nationwide study. Obstetrics and Gynecology 114 (4): 795-804.

NOMESCO. Health Statistics in the Nordic Countries 2007. Nordic MedicoStatistical Committee 84. Copenhagen, 2009. http://nomesco-eng.nom-nos.dk/filer/ publikationer/Helse\%202007.pdf. As accessed 31 August, 2010.

NordForsk. The research programme in Longitudinal Epidemiology: http://www. nordforsk.org/text.cfm?id=426. As accessed 31 August, 2010.

Nordtveit T. I, K. K Melve, S. Albrechtsen, R. Skjaerven. 2008. Maternal and paternal contribution to intergenerational recurrence of breech delivery: population based cohort study. British Medical Journal 336 (7649): 872-6.

OECD. 2010. OECD Health Data 2010. Organisation for Economical Co-operation and Development. Paris 2010. http://www.ecosante.fr/. As accessed 31 August, 2010.

Otterblad Olausson P, C. L. Spetz and M. Rosén. 2004. Stor användning av registerdata i svensk forskning - en nordisk konkurrensfördel (Large use of register data in Swedish research - a Nordic competitive advantage, in Swedish). Norsk Epidemiologi 14: 125-8.

THL. 2009. Pohjoismaiset raskaudenkeskeytystilastot. Nordisk abortstatistik. Nordic statistics on induced abortions.Statistical Report 9/2009. http://www.stakes.fi/EN/tilastot/ statisticsbytopic/reproduction/ nordabortions.htm. As accessed 31 August, 2010.

THL. 2010. Pohjoismaiset perinataalitilastot. Nordisk perinatal statistik. Perinatal Statistics in the Nordic countries. Statistical Report 14/2010. http://www.stakes.fi/ EN/tilastot/statisticsbytopic/reproduction/perinatalreproductionsummary.htm As accessed 31 August, 2010.

Trogstad L, A. Skrondal, C. Stoltenberg, P. Magnus, B. I. Nesheim and A. Eskild. 2004. Recurrence risk of preeclampsia in twin and singleton pregnancies. American Journal of Medical Genetics Part A 2004; 1; 126A(1):41-5.

Virk, J., J. Zhang and J. Olsen. 2007. Medical abortions and the risk of subsequent adverse pregnancy outcomes. New England Journal of Medicine 357 (7): 648-53.

WHO. International Statistical Classification of Diseases and Related Health Problems (10th Edition), World Health Organization. Geneva, 1994.

WHO. European Health for all -database. World Health Organization, Regional Office for Europe. Copenhagen 2010. http://www.euro.who.int/en/what-we-do/ data-and-evidence/databases/european-health-for-all-database-hfa-db2. As accessed 31 August, 2010. 